\title{
Pim kinase inhibition sensitizes FLT3-ITD acute myeloid leukemia cells to topoisomerase 2 inhibitors through increased DNA damage and oxidative stress
}

\author{
Kshama A. Doshi ${ }^{1,2}$, Rossana Trotta ${ }^{1,3}$, Karthika Natarajan ${ }^{1,2}$, Feyruz V. Rassool ${ }^{1,4}$, \\ Adriana E. Tron ${ }^{5}$, Dennis Huszar ${ }^{5, \#}$, Danilo Perrotti ${ }^{1,2}$, Maria R. Baer ${ }^{1,2,6}$ \\ ${ }^{1}$ University of Maryland Greenebaum Cancer Center, University of Maryland School of Medicine, Baltimore, MD, USA \\ ${ }^{2}$ Department of Medicine, University of Maryland School of Medicine, Baltimore, MD, USA \\ ${ }^{3}$ Department of Microbiology and Immunology, University of Maryland School of Medicine, Baltimore, MD, USA \\ ${ }^{4}$ Department of Radiation Oncology, University of Maryland School of Medicine, Baltimore, MD, USA \\ ${ }^{5}$ Oncology iMED, AstraZeneca, Waltham, MA, USA \\ ${ }^{6}$ Veterans Affairs Medical Center, Baltimore, MD, USA \\ \#Present address: Oncology Drug Discovery Unit, Takeda Pharmaceuticals International Co., Cambridge, MA, USA \\ Correspondence to: Maria R. Baer, email: mbaer@umm.edu \\ Keywords: acute myeloid leukemia, FLT3-ITD, Pim kinase, chemotherapy, reactive oxygen species \\ Received: May 15,2016 Accepted: June 09, $2016 \quad$ Published: June 21, 2016
}

\section{ABSTRACT}

Internal tandem duplication of fms-like tyrosine kinase-3 (FLT3-ITD) is frequent (30 percent) in acute myeloid leukemia (AML), and is associated with short diseasefree survival following chemotherapy. The serine threonine kinase Pim-1 is a prosurvival oncogene transcriptionally upregulated by FLT3-ITD that also promotes its signaling in a positive feedback loop. Thus inhibiting Pim-1 represents an attractive approach in targeting FLT3-ITD cells. Indeed, co-treatment with the pan-Pim kinase inhibitor AZD1208 or expression of a kinase-dead Pim-1 mutant sensitized FLT3-ITD cell lines to apoptosis triggered by chemotherapy drugs including the topoisomerase 2 inhibitors daunorubicin, etoposide and mitoxantrone, but not the nucleoside analog cytarabine. AZD1208 sensitized primary AML cells with FLT3-ITD to topoisomerase 2 inhibitors, but did not sensitize AML cells with wild-type FLT3 or remission bone marrow cells, supporting a favorable therapeutic index. Mechanistically, the enhanced apoptosis observed with AZD1208 and topoisomerase 2 inhibitor combination treatment was associated with increased DNA double-strand breaks and increased levels of reactive oxygen species (ROS), and co-treatment with the ROS scavenger $\mathrm{N}$-acetyl cysteine rescued FLT3-ITD cells from AZD1208 sensitization to topoisomerase 2 inhibitors. Our data support testing of Pim kinase inhibitors with topoisomerase 2 inhibitors, but not with cytarabine, to improve treatment outcomes in AML with FLT3-ITD.

\section{INTRODUCTION}

Acute myeloid leukemia (AML) arises in hematopoietic stem/progenitor cells and is characterized by maturation arrest at the level of myeloid blasts [1]. The class III receptor tyrosine kinase fms-like tyrosine kinase-3 (FLT3) is expressed on normal hematopoietic stem/progenitor cells and its signaling is activated by binding of FLT3 ligand [2]. FLT3 is expressed on AML cells in 70-100 percent of cases [2], and internal tandem duplication (ITD) within the FLT3 juxtamembrane domain, conferring constitutive kinase activation [3], is present in 30 percent $[4,5]$.

Patients with AML with FLT3-ITD have poor outcomes with current therapies. Initial treatment of AML consists of remission induction chemotherapy, including combinations of cytotoxic drugs, most commonly the nucleoside analog cytarabine (AraC) and an anthracycline topoisomerase 2 inhibitor, either daunorubicin (DNR) or idarubicin [1]. Other chemotherapy drugs active in AML 
include the topoisomerase 2 inhibitors mitoxantrone (MXR) and etoposide (VP-16) [1]. Post-remission therapy consists of additional chemotherapy, most commonly high-dose AraC, and/or allogeneic hematopoietic stem cell transplantation (alloSCT) [1]. However, FLT3-ITD AML patients relapse rapidly following chemotherapy $[4,5]$ and also following alloSCT [6]. Given the high incidence of FLT3-ITD mutations and their adverse prognostic significance, efforts have been directed toward developing targeted agents that inhibit FLT3 signaling. To date, FLT3 inhibitors used as single agents have limited and transient clinical activity [7-10]. Thus, inhibition of other key molecular targets in the FLT3-ITD pathway is currently being explored.

The Pim kinases Pim-1, Pim-2 and Pim-3 are a family of serine/threonine kinases involved in the regulation of multiple cellular functions including cell cycle, proliferation, apoptosis and drug resistance [11-15]. Pim1 is transcriptionally upregulated by FLT3-ITD-generated signals and directly contributes to the proliferative and anti-apoptotic activity of FLT3-ITD [16]. Moreover Pim-1 phosphorylates and stabilizes FLT3-ITD, thereby promoting FLT3 signaling in a positive feedback loop $[17,18]$. Thus, Pim-1 represents an attractive therapeutic target in AML with FLT3-ITD. Small molecules that inhibit Pim kinases have entered early phase clinical trials [19-22].

Our laboratory showed that concurrent treatment with the pan-Pim kinase inhibitor AZD1208 [20, 23] significantly enhances apoptosis induction by FLT3 inhibitors in cells with FLT3-ITD, in association with synergistic post-translational downregulation of the anti-apoptotic protein Mcl-1 [24]. Here, we sought to determine the effect of Pim kinase inhibition on apoptosis induction by chemotherapy drugs in cells with FLT3-ITD. We focused on chemotherapy drugs used to treat AML, including the topoisomerase 2 inhibitors DNR, MXR and VP-16 and the nucleoside analog AraC.

\section{RESULTS}

\section{Pharmacologic or genetic inactivation of Pim- 1 enhances the growth inhibitory and pro- apoptotic effects of topoisomerase 2 inhibitors in FLT3-ITD cell lines and primary AML cells}

To determine whether inhibition of Pim-1 kinase by the pan-Pim kinase inhibitor AZD1208 enhances the growth inhibitory and pro-apoptotic effects of chemotherapy drugs in FLT3-ITD AML cells, the $\mathrm{IC}_{50}$ concentrations of DNR, MXR, VP-16 and AraC in FLT3-ITD- and FLT3WT-expressing cell lines were first measured using the WST colorimetric assay (Supplementary Figure S1; Supplementary Table S1). Treatment of Ba/F3-ITD cells with DNR or, to a lesser extent, MXR or VP-16 as single agents at their $\mathrm{IC}_{50}$ concentrations, or AZD1208 at $1 \mu \mathrm{M}$, resulted in a time-dependent inhibition of cell proliferation that was enhanced upon co-treatment with AZD1208 (Figure 1A, left, Supplementary Figure S2A). Moreover, AZD1208 enhancement of topoisomerase 2 inhibitor effect was seen preferentially in FLT3-ITD cells, as the effect of AZD1208 and DNR co-treatment on Ba/F3-WT cell growth was more modest (Figure 1A, right).

To determine whether the effect of concurrent treatment with Pim kinase inhibitor and topoisomerase 2 inhibitors on growth of $\mathrm{Ba} / \mathrm{F} 3$-ITD cells was cytotoxic or cytostatic, effects on cell cycle and on induction of apoptosis were studied. While AZD1208 did not alter cell cycle as a single agent (Supplementary Figure S2B), it increased the cytotoxic effect of topoisomerase 2 inhibitors, as demonstrated by a significant $(\mathrm{P}<0.0001)$ increase in percentage of $\mathrm{Ba} / \mathrm{F} 3-\mathrm{ITD}$ cells in the sub-G1 fraction (Figure 1B, left, Supplementary Figure S2B). In contrast, $\mathrm{Ba} / \mathrm{F} 3-\mathrm{WT}$ cells co-treated with AZD1208 and DNR, relative to DNR alone, showed only a modest $(\mathrm{P}<0.05)$ increase in sub-G1 cells (Figure 1B, right). AZD1208 significantly $(\mathrm{P}<0.0001)$ increased topoisomerase 2 inhibitor-induced apoptosis in Ba/F3-ITD, 32D-ITD, MV4-11 and MOLM-14 cells, measured by Annexin V staining (Figure 1C, left, Supplementary Figure 3A, B, left). Increased apoptosis occurred in a time-dependent manner, with a small increase at 24 hours, followed by a progressive increase at 48 and 72 hours in Ba/F3-ITD cells co-treated with AZD1208, compared to topoisomerase 2 inhibitor alone (Figure 1C, right, Supplementary Figure $\mathrm{S} 3 \mathrm{~A}, \mathrm{~S} 3 \mathrm{~B}$, right). $\mathrm{Ba} / \mathrm{F} 3-\mathrm{WT}$ and $32 \mathrm{D}-\mathrm{WT}$ cells were less sensitive than $\mathrm{Ba} / \mathrm{F} 3-\mathrm{ITD}$ and 32D-ITD cells to apoptosis induction by AZD1208 and DNR (Figure 1C, left).

The effect of combined Pim kinase inhibitor and chemotherapy drugs on primary bone marrow and blood cells from AML patients (Supplementary Table S2) was then studied. Co-treatment of FLT3-ITD-expressing primary AML cells with $1 \mu \mathrm{M}$ AZD1208 caused a significant $(\mathrm{P}<0.01)$ concentration-dependent increase in apoptosis induction by topoisomerase 2 inhibitors (Figure 2A, Supplementary Figure S3A, S3B, left). In contrast, cotreatment with AZD1208 did not sensitize primary AML patient cells with FLT3-WT (Figure 2B) or remission bone marrow cells (Figure 2C) to apoptosis induction by topoisomerase 2 inhibitors. Of note, while cells from Patients 5 and 6, with FLT3-WT AML, showed close to maximum induction of apoptosis with DNR alone at 100 $\mathrm{nM}$ and $500 \mathrm{nM}$, respectively, lack of enhanced apoptosis in the presence of AZD1208 was seen at the lower DNR concentrations tested (Figure 2B).

To confirm that sensitization of FLT3-ITD cells to topoisomerase 2 inhibitors by AZD1208 is due to Pim kinase inhibition, rather than to off-target effects, Ba/F3ITD cells expressing kinase-dead (KD) mutant Pim-1 [25, 26] (Figure 3, inset) were studied. DNR-induced apoptosis was significantly $(\mathrm{P}<0.0001)$ greater in $\mathrm{Ba} / \mathrm{F} 3-\mathrm{ITD}$ cells expressing KD mutant Pim-1, compared to empty vector (Figure 3). 
A.

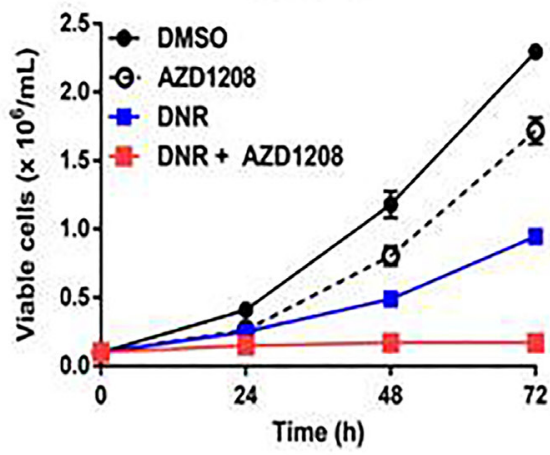

B.

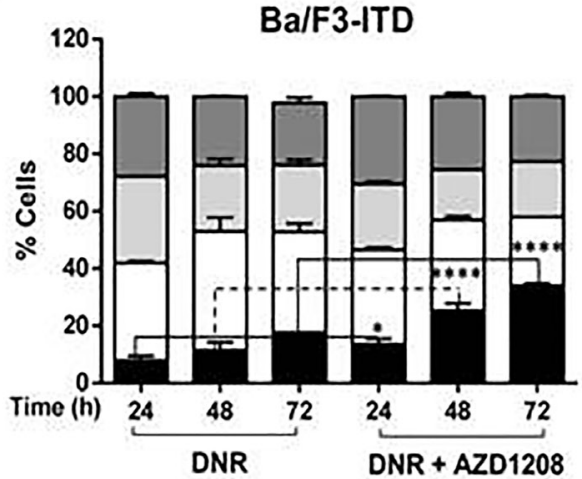

Ba/F3.WT
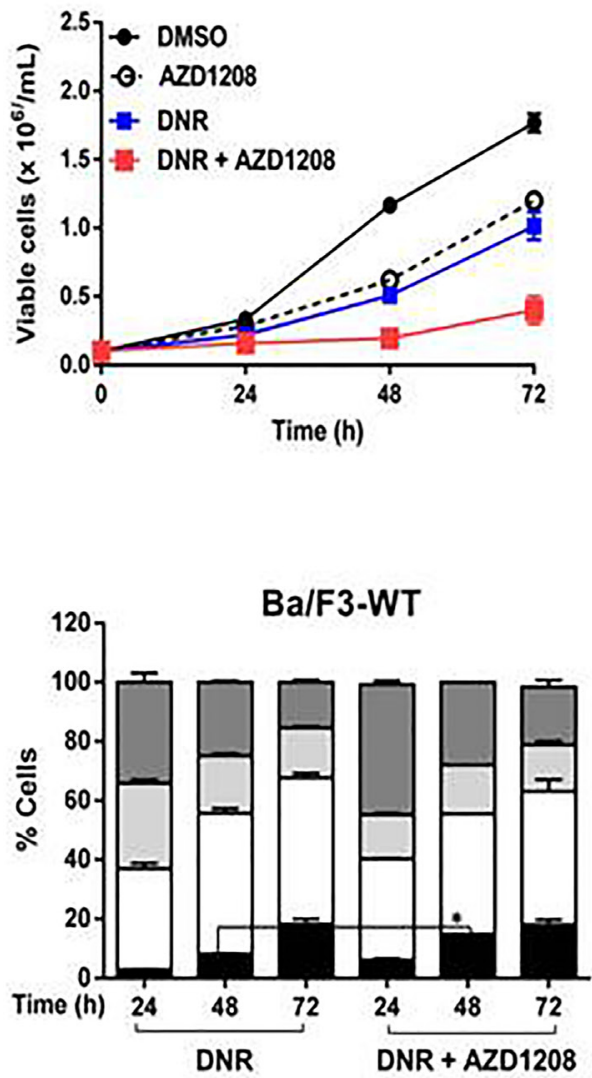

C.
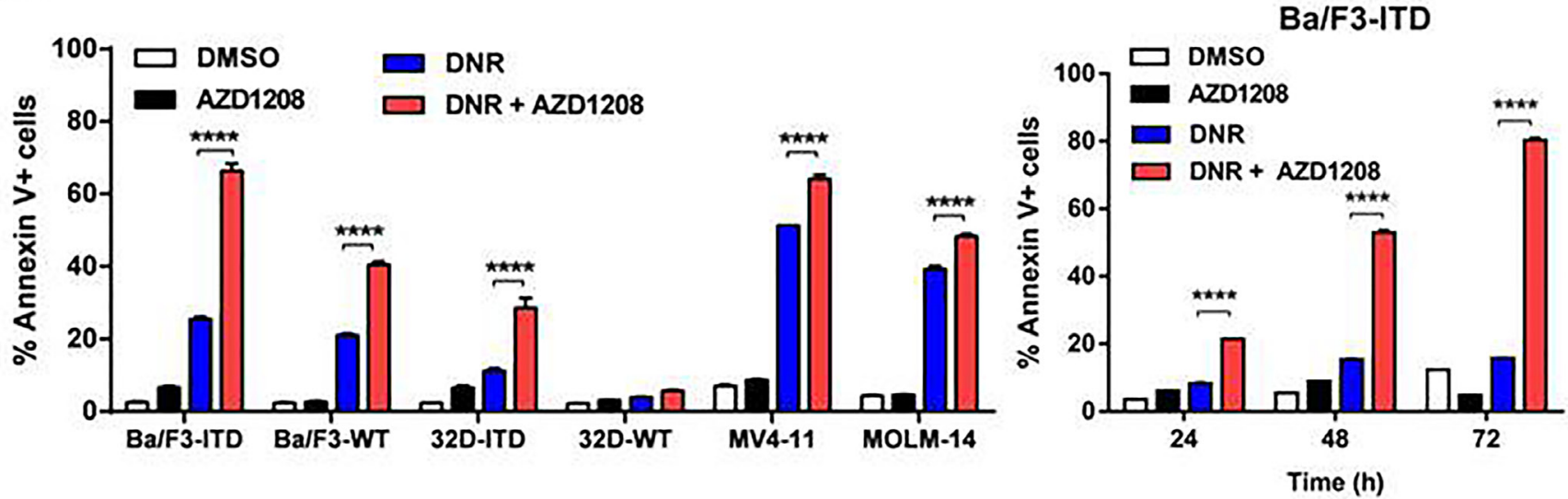

Figure 1: Pim kinase inhibitor sensitizes FLT3-ITD cells to apoptosis induction by topoisomerase 2 inhibitors. A, B. $\mathrm{Ba} / \mathrm{F} 3-\mathrm{ITD}$ and Ba/F3-WT cells were cultured with AZD1208 and/or DNR A. AZD1208 and topoisomerase 2 inhibitor co-treatment abrogates growth of Ba/F3-ITD cells. Viable cells were counted at 24, 48 and 72 hours. A lesser effect was seen in Ba/F3-WT cells co-treated with AZD1208 and DNR. Means \pm S.E.M. of triplicate experiments are shown. B. Sub-G1 Ba/F3-ITD cells increase with AZD1208 and topoisomerase 2 inhibitor co-treatment. Cells were fixed and stained with propidium iodide and percentages of cells in different phases of the cell cycle were analyzed. In contrast to findings in Ba/F3-ITD cells, co-treatment with AZD1208 and DNR, relative to DNR alone, very modestly increased sub-G1 Ba/F3-WT cells. Means \pm S.E.M. of triplicate experiments are shown. C. AZD1208 and topoisomerase 2 inhibitor co-treatment increases Annexin V labeling in FLT3-ITD cells. FLT3-ITD cells, including Ba/F3-ITD, 32D-ITD, MOLM14 and MV4-11, and FLT3-WT cells, including Ba/F3-WT and 32D-WT, were cultured with AZD1208 and/or DNR, and apoptosis was measured at 48 hours by flow cytometric analysis of Annexin V-APC and IR dye labeling. Time-dependent effects of DNR and AZD1208 are shown on the right. Means \pm S.E.M. of triplicate experiments are shown. $* P<0.05, * * * * P<0.0001$. 
A.

FLT3-ITD AML

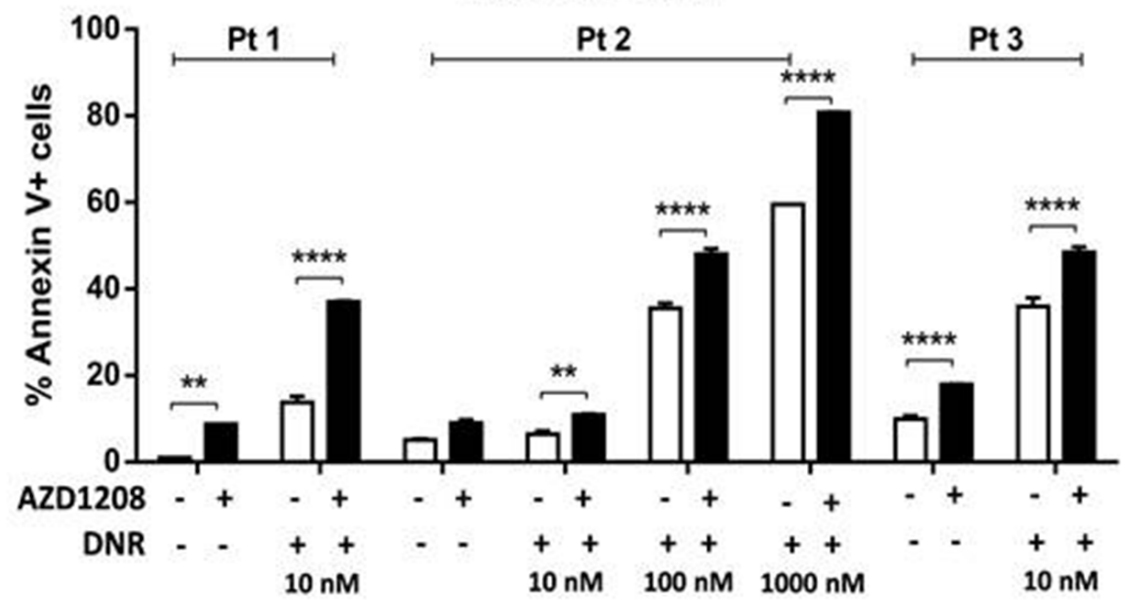

B.

FLT3-WT AML

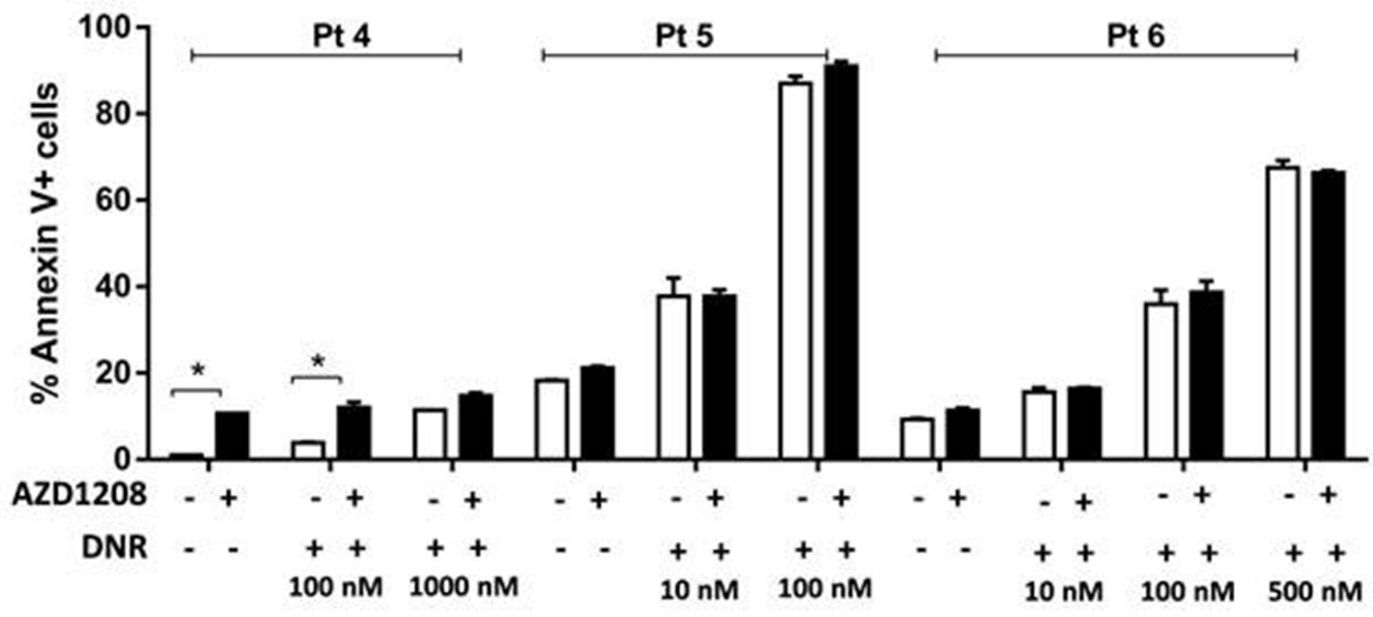

C.

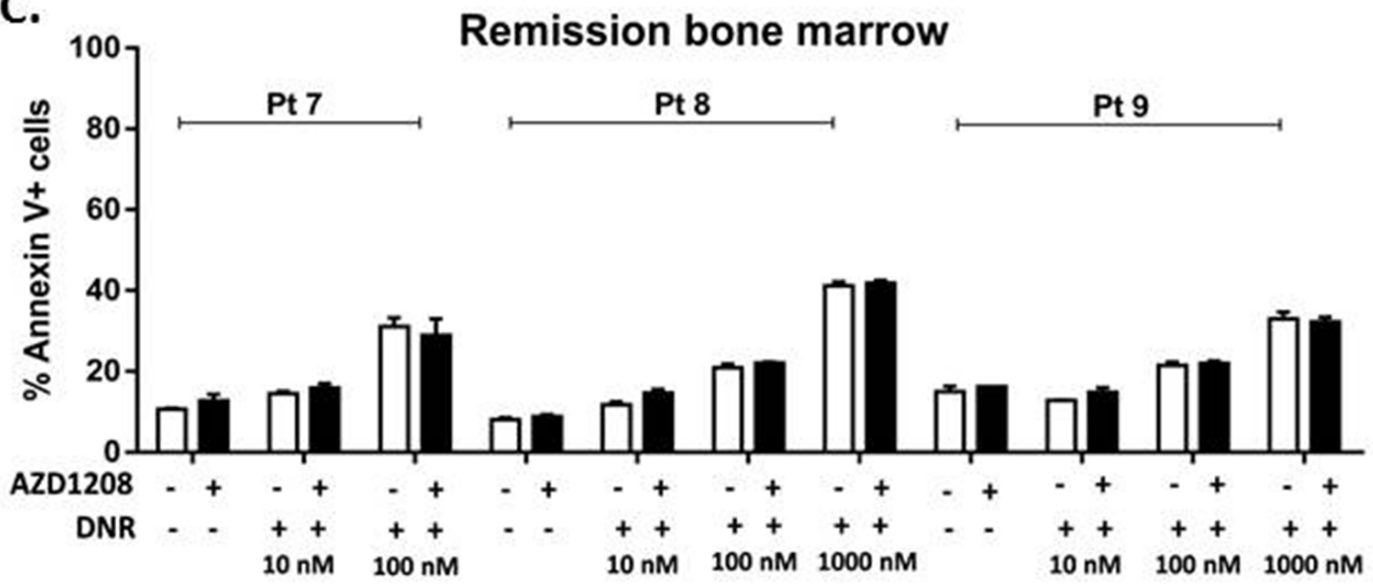

Figure 2: Pim kinase inhibitor sensitizes FLT3-ITD primary AML patient samples, but not FLT3-WT AML or remission bone marrow samples, to apoptosis induction by topoisomerase 2 inhibitors. Mononuclear cells from bone marrow or peripheral blood of A. patients with AML expressing FLT3-ITD or B. patients with AML expressing FLT3-WT or C. remission bone marrow, were treated with AZD1208 and/or DNR. Apoptosis was measured at 48 hours by analysis of Annexin V-APC and IR dye labeling. $* P<0.05, * * P<0.005, * * * * P<0.0001$. 


\section{Inhibition of Pim-1 kinase does not sensitize} FLT3-ITD cells to AraC-induced apoptosis

In contrast to findings with topoisomerase 2 inhibitors, AZD1208 did not enhance the growth inhibitory activity of $\mathrm{AraC}$ in $\mathrm{Ba} / \mathrm{F} 3-\mathrm{ITD}$ cells, and actually modestly protected cells from AraC-induced growth suppression (Figure 4A). Consistent with this lack of enhanced growth suppression, co-treatment with AZD1208 did not sensitize Ba/F3-ITD, 32D-ITD, MV4-11 or MOLM-
14 cells to apoptosis induction by $\mathrm{AraC}$; in fact $\mathrm{Ba} / \mathrm{F} 3$ ITD were modestly protected from apoptosis induction by AraC (Figure 4B). Moreover co-treatment of FLT3ITD-expressing primary AML cells with $1 \mu \mathrm{M}$ AZD1208 did not increase AraC-induced apoptosis (Figure 4B). Similarly, AraC-induced apoptosis of $\mathrm{Ba} / \mathrm{F} 3$-ITD cells was not enhanced in cells expressing the KD mutant Pim-1, and was actually modestly decreased, in relation to empty vector control cells (Figure 4C).
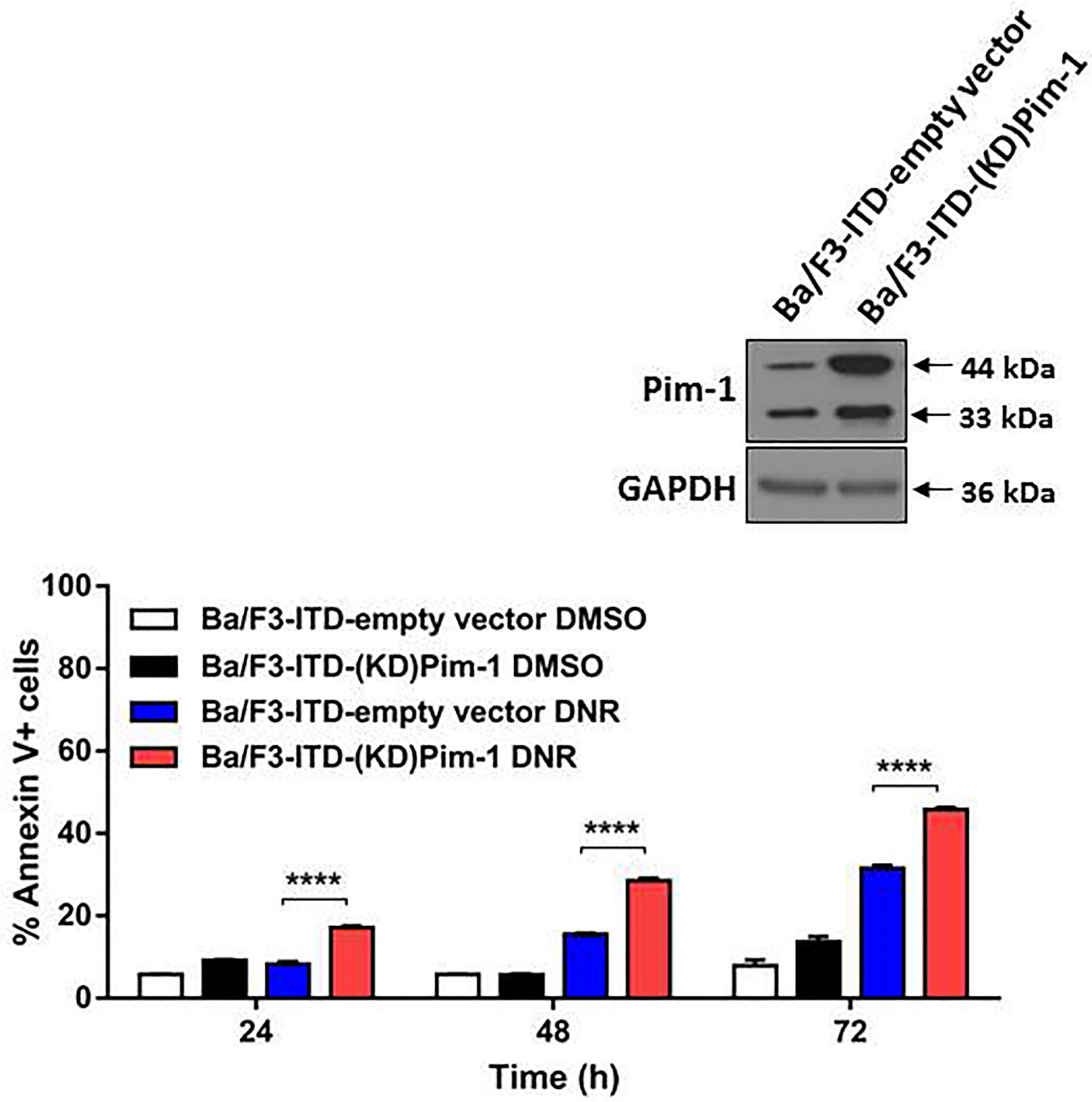

Figure 3: FLT3-ITD cells with kinase-dead mutant Pim-1 kinase are sensitized to apoptosis induction by topoisomerase 2 inhibitor. Ba/F3-ITD cells stably expressing kinase-dead (KD) mutant Pim-1 protein or empty vector were treated with DNR. Total cell lysates were resolved by SDS-PAGE and immunoblotted with Pim-1 and GAPDH primary antibodies. Increased expression of the Pim-1 $44 \mathrm{kDa}$ and $33 \mathrm{kDa}$ isoforms was seen in $\mathrm{Ba} / \mathrm{F} 3-\mathrm{ITD}$ cells expressing $\mathrm{KD}$ mutant Pim-1 protein (inset). Apoptosis was measured by analysis of Annexin V-APC and IR dye labeling. Means \pm S.E.M. of triplicate experiments are shown. $* * * * P<0.0001$. 
A.

$\mathrm{Ba} / \mathrm{F} 3$ - ITD
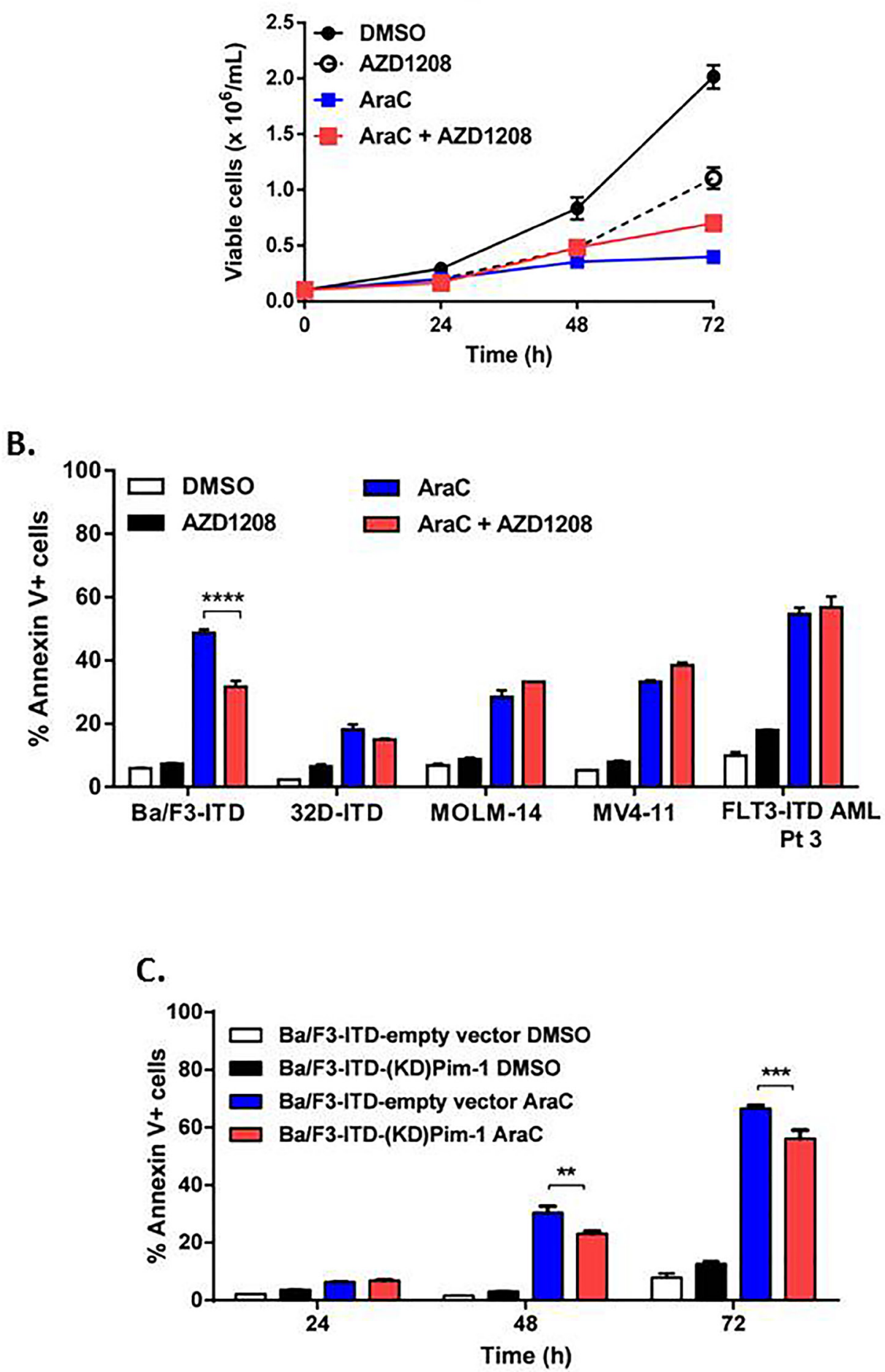

Figure 4: Pim kinase inhibitor does not sensitize cells expressing FLT3-ITD to apoptosis induction by AraC. A. AZD1208 does not enhance AraC suppression of Ba/F3-ITD cell growth. Ba/F3-ITD cells were cultured with AZD1208 and/or AraC and viable cells were counted at 24, 48 and 72 hours. Means \pm S.E.M. of triplicate experiments are shown. B. AZD1208 and AraC co-treatment does not increase Annexin V labeling in FLT3-ITD cells. FLT3-ITD cells, including Ba/F3-ITD, 32D-ITD, MOLM-14 and MV4-11 and mononuclear cells harvested from peripheral blood of a patient with AML expressing FLT3-ITD, were cultured with AZD1208 and/ or AraC. Apoptosis was measured at 48 hours by analysis of Annexin V-APC and IR dye. Means \pm S.E.M. of triplicate experiments are shown. C. FLT3-ITD cells with kinase-dead mutant Pim-1 kinase are not sensitized to apoptosis induction by AraC. Ba/F3-ITD cells stably expressing kinase-dead (KD) mutant Pim-1 protein or empty vector were treated with AraC. Apoptosis was measured by analysis of Annexin V-APC and IR dye labeling. Means \pm S.E.M. of triplicate experiments are shown. $* * P<0.005, * * * P<0.0005, * * * * P<0.0001$. 


\section{Pim kinase inhibitor enhances apoptosis of FLT3-ITD cells by topoisomerase 2 inhibitors via intrinsic cell death signaling}

We then sought to determine whether enhanced apoptosis induction in FLT3-ITD cells by Pim kinase and topoisomerase 2 inhibitor co-treatment occurs via the intrinsic or the extrinsic cell death pathway. Co-treatment with AZD1208 and topoisomerase 2 inhibitors caused significantly $(\mathrm{P}<0.0001)$ greater decrease of mitochondrial membrane potential (MMP) (Figure 5A, Supplementary Figure S4A, S4B) and greater release of cytochrome $c$ into the cytoplasm (Figure 5A, Supplementary Figure S4A, S4B), relative to topoisomerase 2 inhibitors alone, consistent with increased intrinsic cell death signaling. Additionally co-treatment with AZD1208 and DNR, compared to DNR alone, caused more pronounced cleavage of caspase 3 and its substrate PARP (Figure 5A, $5 \mathrm{~B})$. Increased caspase 3 cleavage was also seen in $\mathrm{Ba} / \mathrm{F} 3$ ITD cells co-treated with AZD1208 and VP-16 or MXR (Supplementary Figure S4A, S4B). Moreover, enhanced caspase 3 cleavage was blocked and apoptosis was decreased by co-incubation with the pan-caspase inhibitor Z-VAD FMK $(\mathrm{P}<0.0001)$ (Supplementary Figure $\mathrm{S} 4 \mathrm{C})$, highlighting the role of caspase activation in enhanced apoptosis induction by AZD1208 and topoisomerase 2 inhibitor co-treatment.

While we previously showed that enhanced apoptosis of FLT3-ITD cells co-treated with AZD1208 and FLT3 inhibitors is associated with downregulation of the anti-apoptotic protein Mcl-1 [24], Mcl-1 levels decreased similarly in $\mathrm{Ba} / \mathrm{F} 3-\mathrm{ITD}$ cells treated with DNR with and without AZD1208 (Supplementary Figure S4D), indicating that decreased Mcl-1 expression is not the mechanism for the combination effect. Expression of other pro-apoptotic and anti-apoptotic proteins, including Bad, Bim, Bax, Bak, Bcl-xl and Bcl2, also did not differ significantly (data not shown).

Additionally, co-treatment with AZD1208 did not enhance AraC-induced loss of MMP, cytochrome $c$ release or caspase 3 cleavage in $\mathrm{Ba} / \mathrm{F} 3-\mathrm{ITD}$ cells, and actually modestly protected from AraC-induced loss of MMP $(\mathrm{P}<0.0001)$ (Figure 5C) and decreased cytochrome $c$ release $(\mathrm{P}<0.01)$ (Figure $5 \mathrm{C})$ and caspase 3 cleavage $(\mathrm{P}<0.01)$ (Figure 5C).

\section{Pim kinase inhibitor enhances induction of DNA damage and ROS generation by topoisomerase 2 inhibitors, but not by AraC, in cells with FLT3-ITD}

Topoisomerase 2 inhibitors stabilize the topoisomerase 2 enzyme during DNA replication, thereby causing collapse of the replication fork, which results in DNA double-strand breaks (DSBs) and subsequent cell death $[27,28]$. Phosphorylated histone $\mathrm{H} 2 \mathrm{AX}\left(\gamma-\mathrm{H}_{2} \mathrm{AX}\right)$, a marker for DNA DSBs [29, 30], increased more than two-fold within 8 hours of concurrent treatment of $\mathrm{Ba} / \mathrm{F} 3$ ITD cells with AZD1208 and topoisomerase 2 inhibitors, relative to topoisomerase 2 inhibitors alone, with subsequent sustained increase (Figure 6A, Supplementary Figure S5A, S5B). DNA damage induces oxidative stress, which leads to further DNA damage, creating a positive feedback loop that triggers cell death [31, 32]. AZD1208 and topoisomerase 2 inhibitor combination treatment caused minimal induction of ROS in Ba/F3-ITD cells up to 24 hours, followed by a two-fold increase at later time points, relative to treatment with topoisomerase 2 inhibitors alone (Figure 6B, Supplementary Figure S6A). Pretreatment of $\mathrm{Ba} / \mathrm{F} 3$-ITD cells with the ROS scavenger NAC reduced ROS induction (Supplementary Figure S6B), as expected, and decreased induction of $\gamma-\mathrm{H}_{2} \mathrm{AX}$ expression by the combination treatment (Figure 6C, left). Moreover, apoptosis was markedly attenuated when $\mathrm{Ba} /$ F3-ITD cells were treated with NAC before AZD1208 and topoisomerase 2 inhibitor combination treatment $(\mathrm{P}<0.001)$ (Figure 6C, right, Supplementary Figure $\mathrm{S} 6 \mathrm{C})$. Finally, the lack of potentiation of AraC-induced apoptosis by Pim kinase inhibition reflects reduced AraCmediated DNA damage (Figure 7A) and lack of increased ROS generation (Figure 7B) with concurrent AZD1208 treatment.

\section{DISCUSSION}

Patients with AML with FLT3-ITD generally achieve remission following induction chemotherapy, but they have a high relapse rate and short disease-free survival $[3,4,6]$. As responses to FLT3 kinase inhibitors used as single agents are incomplete and transient, [7-10] additional targets in the FLT3-ITD signaling pathway are being explored as a basis for novel therapies. Because of the central role of Pim-1 in FLT3-ITD signaling [17, 18], and the ability of Pim kinase inhibitors to sensitize FLT3-ITD AML cells to FLT3 inhibitor-induced apoptosis $[17,18,24,33]$, we investigated the effects of Pim kinase inhibition on apoptosis induction by chemotherapy drugs in FLT3-ITD AML cells. We focused on chemotherapy drugs used to treat AML, including the topoisomerase 2 inhibitors DNR, VP-16 and MXR and the nucleoside analog $\mathrm{AraC}$ [1]. We used $\mathrm{Ba} / \mathrm{F} 3$ as our main cell system to evaluate the differential effect of inhibiting Pim kinase in cells expressing FLT3-ITD (Ba/F3-ITD) vs FLT3-WT $(\mathrm{Ba} / \mathrm{F} 3-\mathrm{WT})$, and subsequently studied another paired set of cell lines, 32D-ITD and 32D-WT, human cell lines and, importantly, primary AML cells. Ba/F3-WT and 32D-WT cells were cultured with interleukin-3 (IL-3) due to their cytokine dependence, while $\mathrm{Ba} / \mathrm{F} 3-\mathrm{ITD}$ and 32D-ITD cells are cytokine-independent $[34,35] . \mathrm{Ba} / \mathrm{F} 3-\mathrm{ITD}$ cells were also studied in the presence of IL-3, with no effect on apoptosis induction by topoisomerase 2 inhibitor and AZD1208 co-treatment (data not shown). Primary 

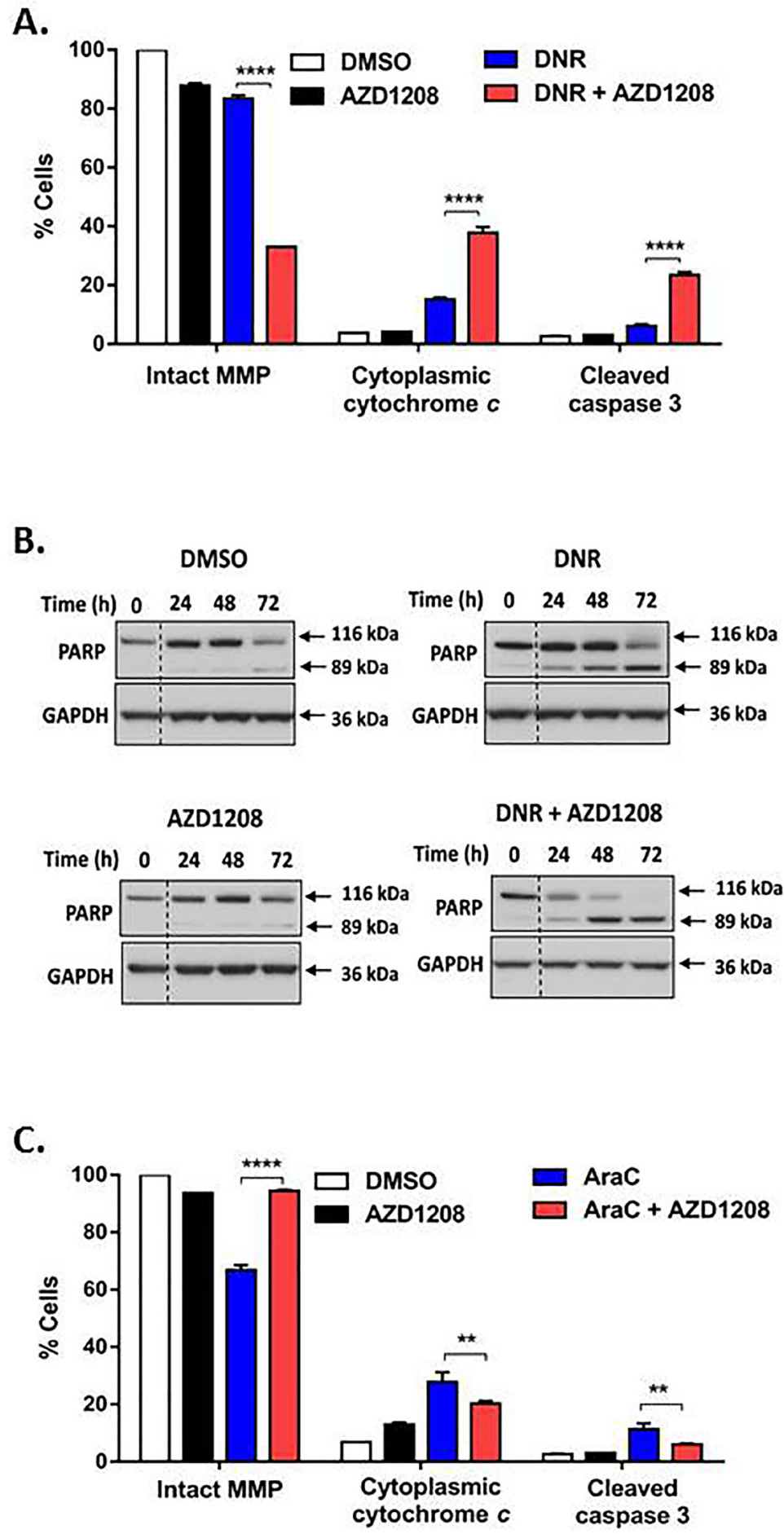

Figure 5: Pim kinase inhibitor and topoisomerase 2 inhibitor co-treatment increases intrinsic cell death signaling in FLT3-ITD cells. A. AZD1208 and topoisomerase 2 inhibitor co-treatment induces loss of mitochondrial membrane potential (MMP), increase in cytoplasmic cytochrome $c$ and cleavage of caspase 3. Ba/F3-ITD cells cultured with AZD1208 and/or DNR were collected at 48 hours. To measure MMP, cells were incubated with JC-1 dye and median red fluorescence was measured. To measure cytoplasmic cytochrome $c$ and caspase 3 cleavage, cells were permeabilized, fixed, blocked and incubated with FITC-labeled antiCytochrome $c$ and FITC-labeled anti-Active Caspase 3, respectively. Means \pm S.E.M. of triplicate experiments are shown. B. AZD1208 and topoisomerase 2 inhibitor co-treatment increases PARP cleavage. Ba/F3-ITD cells were cultured with AZD1208 and/or DNR. Total cell lysates were resolved by SDS-PAGE and immunoblotted with PARP and GAPDH primary antibodies. Representative immunoblots are shown. C. Co-treatment with AZD1208 does not increase intrinsic cell death signaling induced by AraC. Ba/F3-ITD cells were cultured with AZD1208 and/or AraC. MMP, cytoplasmic cytochrome $c$ and caspase 3 cleavage were measured as described above. Means \pm S.E.M. of triplicate experiments are shown. $* * P<0.01, * * * * P<0.0001$. 
A.

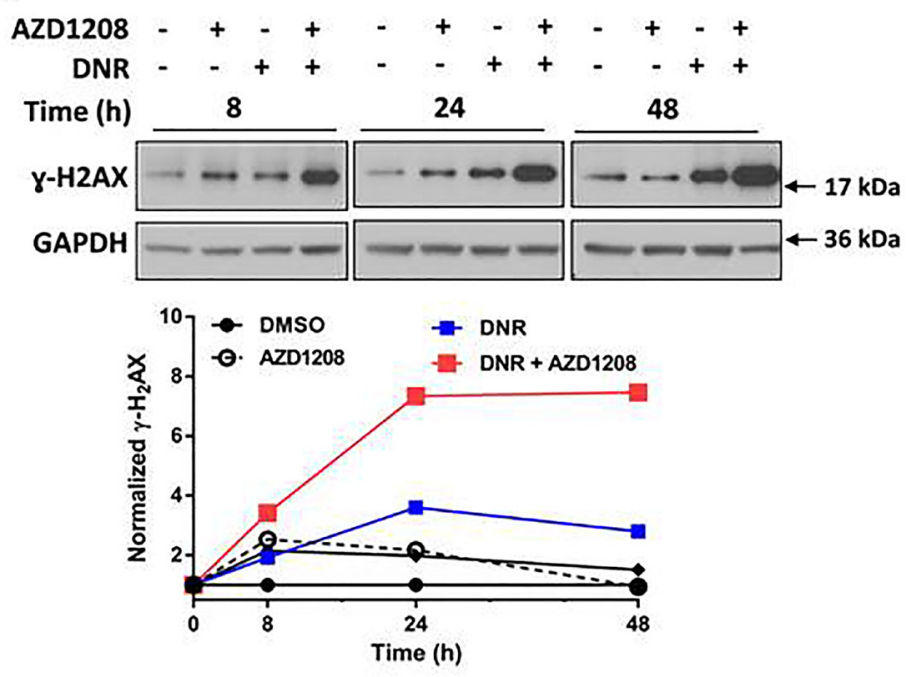

B.

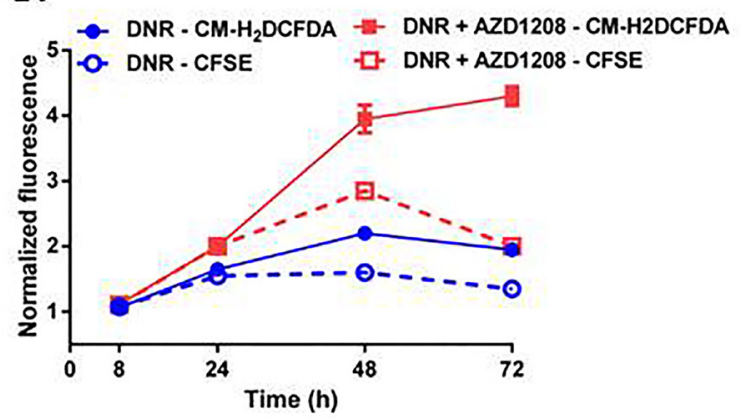

C.
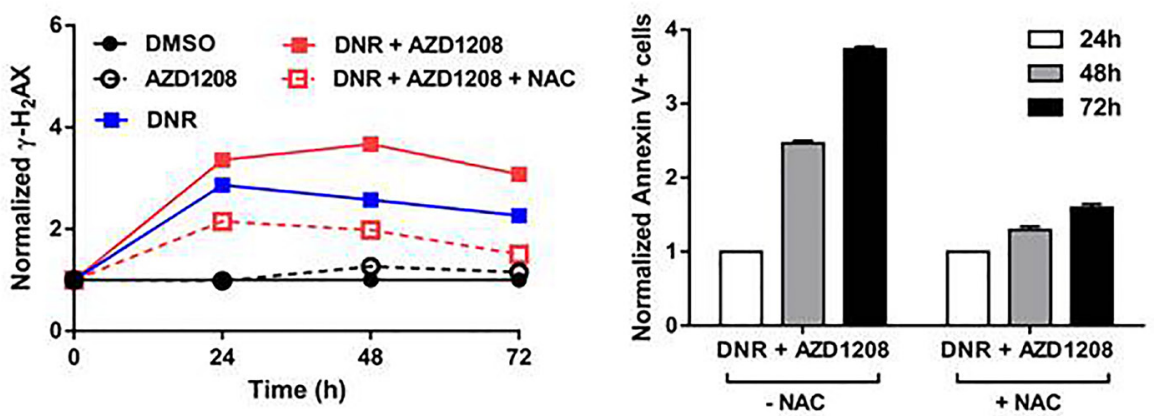

Figure 6: Pim kinase inhibitor enhances induction of DNA damage and ROS generation by topoisomerase 2 inhibitors in cells with FLT3-ITD. A. Concurrent treatment with Pim kinase inhibitor and topoisomerase 2 inhibitor increases DNA double-strand breaks. Ba/F3-ITD cells were treated with AZD1208 and/or DNR. Total cell lysates were resolved by SDS-PAGE and immunoblotted with $\mathrm{\gamma}-\mathrm{H} 2 \mathrm{AX}$ and GAPDH primary antibodies. Densitometry was performed and intensities at serial time points were plotted relative to pre-treatment levels, defined as 1. Representative immunoblots are shown. B. Concurrent treatment with Pim kinase inhibitor and topoisomerase 2 inhibitor increases ROS induction. Ba/F3-ITD cells incubated with CM-H DCFDA and CFSE dyes to measure intracellular ROS (solid lines) and cell proliferation (dashed lines), respectively, were treated with AZD1208 and/or DNR. Fluorescence normalized to DMSO at serial time points was plotted relative to pre-treatment levels, defined as 1. Greater CM- ${ }_{2}$ DCFDA fluorescence (solid lines) than CFSE fluorescence (dashed lines) indicates ROS generation. Means \pm S.E.M. of triplicate experiments are shown. C. The ROS scavenger NAC decreases DNA double-strand breaks and attenuates apoptosis induction by AZD1208 and topoisomerase 2 inhibitor co-treatment. Ba/F3-ITD cells were treated with AZD1208 and/or DNR in the presence and absence of NAC. (left) Total cell lysates were resolved by SDS-PAGE and immunoblotted with $\mathrm{\gamma}-\mathrm{H} 2 \mathrm{AX}$ and GAPDH primary antibodies. Densitometry was performed and intensities at serial time points were plotted relative to pre-treatment levels, defined as 1 (left). Apoptosis was measured by flow cytometric analysis of Annexin V-APC and IR dye labeling. Fold apoptosis at serial time points was plotted relative to apoptosis at 24 hours, defined as 1. Means \pm S.E.M. of triplicate experiments are shown (right). 
A.
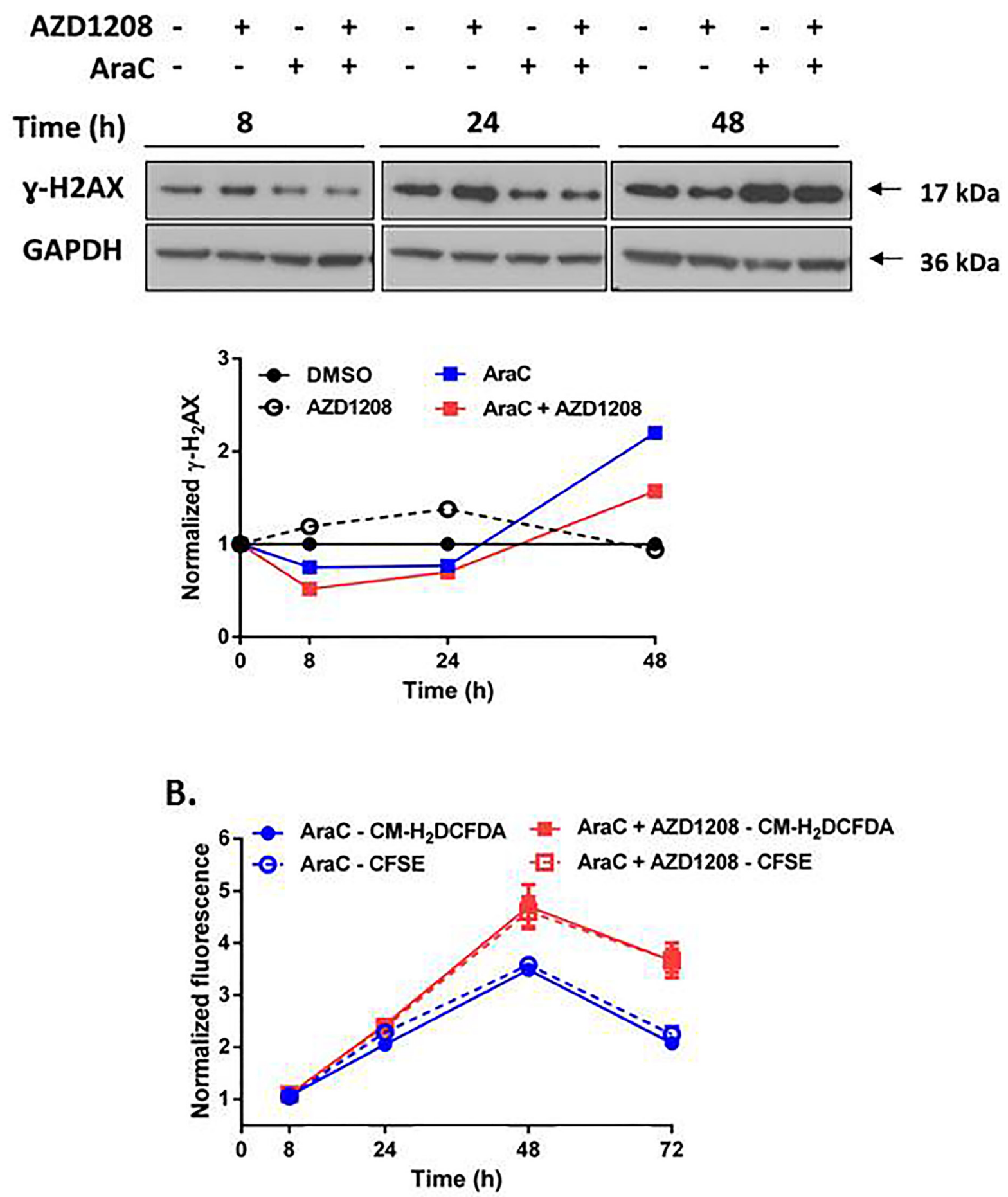

Figure 7: Pim kinase inhibitor does not enhance induction of DNA damage and ROS generation by AraC in cells with FLT3-ITD. A. Concurrent treatment with Pim kinase inhibitor and AraC does not increase DNA double-strand breaks. $\mathrm{Ba} /$ F3-ITD cells were treated with AZD1208 and/or AraC. Total cell lysates were resolved by SDS-PAGE and immunoblotted with y-H2AX and GAPDH primary antibodies. Densitometry was performed and intensities at serial time points were plotted relative to pre-treatment levels, defined as 1. Representative immunoblots are shown. B. Concurrent treatment with Pim kinase inhibitor and AraC does not increase ROS induction. Ba/F3-ITD cells incubated with CM- $\mathrm{H}_{2}$ DCFDA and CFSE dyes to measure intracellular ROS (solid lines) and cell proliferation (dashed lines), respectively, were treated with AZD1208 and/or AraC. Fluorescence normalized to DMSO at serial time points was plotted relative to pre-treatment levels, defined as 1. Overlap of CM- $\mathrm{H}_{2}$ DCFDA fluorescence with CFSE fluorescence indicates lack of ROS generation. Means \pm S.E.M. of triplicate experiments are shown. 
FLT3-ITD and FLT3-WT AML cells and remission bone marrow cells were cultured under similar conditions, with FBS only, without additional cytokine supplementation.

While the Pim kinase inhibitor AZD1208 had minimal cytotoxic effects as a single agent, consistent with findings in previous work $[23,24]$, when combined with topoisomerase 2 inhibitors it increased intrinsic apoptosis signaling in FLT3-ITD cells, leading to enhanced apoptosis. In contrast, AZD1208 did not sensitize FLT3ITD cells to induction of apoptosis by AraC. Sensitization to topoisomerase 2 inhibitors, but not to $\mathrm{AraC}$, was also seen in $\mathrm{Ba} / \mathrm{F} 3-\mathrm{ITD}$ cells expressing kinase dead mutant Pim-1, confirming Pim kinase inhibition, rather than off-target effects, as the mechanism for the effect of AZD1208 on topoisomerase 2 inhibitor-induced apoptosis. Sensitization to topoisomerase 2 inhibitors was also seen in FLT3-ITD AML patient samples, but not in FLT3-WT AML patient samples or AML remission bone marrow samples. Lack of sensitization of AML remission bone marrow samples suggests a favorable therapeutic index relative to normal hematopoietic cells.

Pim kinases promote survival of cancer cells through effects on multiple cellular processes, including proliferation, cell cycle and apoptosis [11-15]. The likely existence of compensatory mechanisms among the three isoforms of Pim kinase, Pim-1, Pim-2 and Pim-3, supports the utility of developing pan-Pim kinase inhibitors [36]. Four Pim kinase inhibitors have entered clinical trials to date. SGI-1776 [19], which inhibits both Pim kinase and FLT3, showed clinical activity in phase I testing in AML, but is no longer in development due to excessive QT prolongation [37]. AZD1208, the ATP-competitive panPim kinase inhibitor used in our work here, had clinical activity at well tolerated doses in phase I clinical testing in AML [20] but clinical development was discontinued due to highly variable pharmacokinetics and time-dependent decrease in exposure (personal communication). PIM447, previously LGH447 [21], and INCB53914 [22], both panPim kinase inhibitors, are currently in clinical trials. We have subsequently also demonstrated enhanced apoptosis of FLT3-ITD cells treated with PIM447 in combination with topoisomerase inhibitors [38].

Pim kinase inhibition sensitizes FLT3-ITD cell lines and primary AML cells to induction of apoptosis by topoisomerase 2 inhibitors through enhanced DNA damage and increased oxidative stress. Increase in DNA DSBs was seen at 8 hours of co-treatment in the absence of increased ROS, followed by progressive induction of ROS and further DNA DSBs. Based on the kinetics of DNA DSB and ROS induction, the initial small increase in apoptosis at 24 hours in FLT3-ITD cells co-treated with AZD1208 and topoisomerase 2 inhibitors is attributable to increased DNA DSBs, which then induce oxidative stress and further DNA damage, causing the subsequent marked progressive increase in apoptosis. Protection of $\mathrm{Ba} / \mathrm{F} 3-\mathrm{ITD}$ cells treated with the ROS scavenger NAC from increased apoptosis induction by combined Pim and topoisomerase 2 inhibitor treatment proves the key role of ROS induction in enhanced apoptosis.

Increased oxidative stress plays a key role in apoptosis induction by many chemotherapy drugs and small molecules [39-44]. In particular, the topoisomerase 2 inhibitors studied here are known to induce oxidative stress [45, 46]. Cellular DNA damage also increases oxidative stress [47], mediated at least in part by the p53 or H2AX/Nox1/Rac1 pathway [48]. Increased oxidative stress in turn oxidizes DNA base pairs, inducing DNA strand breaks and thereby creating a positive feedback loop $[31,32]$ leading to greater oxidative stress. Moreover, Pim kinase triple-knockout cells were recently reported to have increased levels of ROS, sensitizing them to K-Rasinduced cell killing [49].

The role of ROS in FLT3-ITD AML is complex. FLT3-ITD cells have high baseline ROS levels [50] which are associated with increased DNA damage. DNA damage is repaired by the error-prone alternative non-homologous end-joining (alt-NHEJ) pathway, resulting in genomic instability and disease progression $[50,51]$. High levels of ROS in FLT3-ITD cells also inactivate the protein tyrosine phosphatase DEP-1/PTPRJ through oxidation of the DEP-1 catalytic cysteine, and DEP-1/PTPRJ inactivation contributes to cell transformation by FLT3-ITD [52]. On the other hand, we have shown that inhibition of Pim kinases sensitizes cells with FLT3-ITD to apoptosis induction by topoisomerase 2 inhibitors through increased ROS generation, in that marked increase in ROS is seen and enhanced apoptosis induction is inhibited by coincubation with the ROS scavenger NAC. We hypothesize that increased baseline ROS levels in FLT3-ITD cells may sensitize them to ROS-dependent enhanced apoptosis by Pim kinase inhibitor and topoisomerase 2 inhibitor cotreatment. Recent work by several groups has focused on susceptibility of AML cells [53] and AML stem cells [53, 54] to oxidative stress, but this work has not focused on AML with FLT3-ITD in particular.

Pim kinase inhibition might also increase the DNA DSBs induced by topoisomerase 2 inhibitors by decreasing DNA DSB repair. Topoisomerase 2 inhibitors induce DNA damage by stabilizing the topoisomerase 2:DNA complex, which causes disruption of the replication fork, leading to DNA DSBs [27, 28]. DNA DSBs induced by topoisomerase 2 inhibitors are repaired by the homologous recombination (HR) and classical NHEJ pathways $[55,56]$. Doxorubicin-induced DNA damage was significantly increased in lymphoma cell lines exposed to a Pim kinase inhibitor, in association with significant downregulation of the DNA DSB response proteins H2AX, ATM and Chk2 [57]. Similarly, inhibition of Pim kinase in T-cell lymphoma cells downregulated genes involved in DNA repair, including XRCC2 (HR), XRCC5 (encoding Ku80, in the NHEJ pathway), and ERCC8 (nucleotide excision repair) [36]. Pim kinase 
inhibition was also found to potentiate paclitaxel-induced apoptosis through decreased repair via the NHEJ pathway, with inhibition of ATM, DNA-PKcs and Ku activity and/ or expression [58]. Notably, cells with FLT3-ITD exhibit downregulation of classical NHEJ, and upregulation of the alt-NHEJ pathway, which is error-prone [50, 51]. The role of Pim-1 kinase in alt-NHEJ in FLT3-ITD cells is unknown. Further studies will address whether cotreatment with Pim kinase inhibitor decreases repair of DNA DSBs induced by topoisomerase 2 inhibitors, and identify the relevant repair pathways.

Potentiation of topoisomerase 2 inhibitor-induced apoptosis by Pim inhibition was much greater in cells with FLT3-ITD than in cells with FLT3-WT. Upregulated Pim1 expression [16], higher baseline ROS levels [50] and increased genomic instability in FLT3-ITD cells relative to FLT3-WT cells [51] likely explain this difference in sensitivity. Moreover lack of sensitization of remission bone marrow cells may predict that concurrent treatment with Pim kinase and topoisomerase 2 inhibitors in the clinical setting will be associated with a favorable therapeutic index for FLT3-ITD AML cells in relation to normal hematopoietic cells.

Pim kinase inhibition did not sensitize cells with FLT3-ITD to AraC, and actually modestly decreased induction of apoptosis by AraC. The lack of sensitization correlated with reduced DNA DSBs and lack of induction of ROS in FLT3-ITD cells co-treated with the Pim inhibitor and AraC. This is likely due to slower proliferation of FLT3-ITD cells in response to Pim inhibition, which in turn decreases the fraction of cells in S-phase, thereby decreasing the efficacy of AraC, which must be incorporated into DNA in S-phase.

These preclinical studies suggest that concurrent treatment with a Pim kinase inhibitor has the potential to sensitize AML cells with FLT3-ITD to the cytotoxic effects of topoisomerase 2 inhibitors, but not AraC. We have previously also demonstrated enhanced apoptosis of FLT3-ITD AML cells concurrently treated with Pim kinase inhibitors and FLT3 inhibitors $[17,24]$. Together, our data support the potential efficacy of combining Pim kinase inhibitors with topoisomerase- 2 inhibitors and with FLT3 inhibitors, likely administered sequentially, in novel treatment regimens for FLT3-ITD AML.

\section{MATERIALS AND METHODS}

\section{Cell lines}

FLT3-ITD- and FLT3-WT-transfected BaF3 cells (Ba/F3-ITD and Ba/F3-WT; kind gift of Dr. M. Levis, Johns Hopkins University School of Medicine, Baltimore, MD) [59] and 32Dcl3 cells (32D-ITD and 32D-WT) [50] and MV4-11 and MOLM-14 human AML cells with FLT3-ITD [60] were maintained in RPMI 1640 with 10 percent fetal bovine serum (FBS). Ba/F3-WT and 32D-
WT cell cultures were supplemented with $10 \mathrm{ng} / \mathrm{ml}$ IL-3, due to the cytokine dependence of these cells $[34,35]$.

\section{Infection of Ba/F3-ITD cells with kinase-dead mutant Pim-1}

$\mathrm{Ba} / \mathrm{F} 3-\mathrm{ITD}$ cells were infected with pMX-FlagK67M kinase-dead (KD)Pim-1 and empty pMX retroviral vectors, as previously described $[25,26]$. Cells were collected 24 hours after infection and cultured for 96 hours with puromycin for selection. Increased Pim-1 protein expression in cells infected with (KD)Pim-1 was confirmed by immunoblotting.

\section{Patient samples}

Mononuclear cells were isolated by density centrifugation over Ficoll-Paque (Sigma-Aldrich, St Louis, MO) from bone marrow or blood of 6 AML patients at diagnosis and bone marrow from 3 patients in remission on a University of Maryland Baltimore Institutional Review Board-approved protocol. Cells were studied without prior crypreservation. Primary FLT-3-ITD and FLT3-WT AML cells and remission bone marrow cells were cultured in RPMI 1640 with 10 percent FBS, without additional cytokine supplementation.

\section{Materials}

The pan-Pim kinase inhibitor AZD1208 was provided by AstraZeneca (Waltham, MA). AZD1208 was used at 1 $\mu \mathrm{M}$ based on phase I clinical trial data [20] and inhibition of Bad phosphorylation at serine 112 as a pharmacodynamic endpoint [15]. DNR, MXR, VP-16, AraC and N-acetyl cysteine (NAC) (Sigma-Aldrich) were dissolved in phosphate buffered saline solution or DMSO (less than 0.05 percent) as per the manufacturer's recommendations.

\section{Cell proliferation assay}

Cultured cells were collected at 24, 48 and 72 hours and live cells were counted after trypan blue dye exclusion.

\section{Cytotoxicity assay}

Cytotoxicity was measured using the WST colorimetric assay, as previously described [61]. Briefly, 5,000 log-phase cells per well were incubated in $100 \mu \mathrm{L}$ complete medium with chemotherapy drugs at increasing concentrations in 96-well plates for 48 hours. The tetrazolium salt WST-1 (Roche Diagnostics, Indianapolis, IN) was then added, cells were incubated for 2 to 4 hours and metabolically active cells were measured spectrophotometrically at $450 \mathrm{nM}$. $\mathrm{IC}_{50}$ values were determined by non-linear curve fitting to dose-response curves, using Prism V (GraphPad, La Jolla, CA). 


\section{Cell cycle analysis}

Cells collected at 24, 48 and 72 hours were fixed in ethanol, treated with DNase-free RNase, stained with propidium iodide (PI) for 15 minutes and analyzed on a FACSCanto II flow cytometer (BD Biosciences, San Jose, CA). Percentages of cells in different cell cycle phases were determined using FlowJo software (Tree Star, Inc., Ashland, OR).

\section{Measurement of apoptosis by Annexin V staining}

Apoptosis was measured by flow cytometric detection of Annexin V-FITC and PI (experiments with MXR and VP-16) or Annexin V-APC and IR dye (experiments with DNR and AraC), as previously described [61].

\section{Measurement of mitochondrial membrane potential}

Mitochondrial membrane potential (MMP) was measured using the MitoProbe ${ }^{\mathrm{TM}}$ JC-1 Assay Kit (Life Technologies, Grand Island, NY). Briefly, cells were incubated with $\mathrm{JC}-1$ dye at $37^{\circ} \mathrm{C}$ for 30 minutes, and median red fluorescence was measured on a FACSCanto II and analyzed using FlowJo.

\section{Measurement of cytoplasmic cytochrome $c$}

Cytoplasmic cytochrome $c$ was measured with the FlowCellect ${ }^{\mathrm{TM}}$ Cytochrome $c$ kit (EMD Millipore, Billerica, MA). Briefly, cells were permeabilized, fixed, blocked and incubated with anti-Cytochrome $c$-FITC for 30 minutes. Samples were acquired on a FACSCanto II and analyzed using FlowJo.

\section{Measurement of caspase 3 activation}

Cleaved caspase 3 was measured with the FITC Active Caspase 3 Apoptosis Kit (BD Pharmingen, San Jose, CA). Briefly, cells were permeabilized, fixed and incubated with FITC-labeled anti-Active Caspase 3 for 30 minutes. Samples were acquired on a FACSCanto II and analyzed using FlowJo.

\section{Immunoblotting}

Cells were lysed in RIPA buffer (Sigma-Aldrich) with protease and phosphatase inhibitors (Roche Applied Science, Indianapolis, IN) and whole cell lysates were subjected to immunoblotting as previously described [61]. Primary antibodies to poly (ADP-ribose) polymerase (PARP), Mcl-1, Pim-1 (Cell Signaling Technology, Danvers, MA), $\gamma \mathrm{H} 2 \mathrm{AX}$ (EMD Milipore) and glyceraldehyde 3-phosphate dehydrogenase (GAPDH) (Calbiochem, San Diego, CA) were used. Densitometry was performed with VisionWorks LS Image Acquisition and Analysis Software (UVP, Upland, CA).

\section{Measurement of reactive oxygen species}

Reactive oxygen species (ROS) were measured using the redox-sensitive dye CM- $\mathrm{H}_{2}$ DCFDA (Invitrogen, Grand Island, NY). To control for altered dye retention due to cell division, another aliquot of cells was simultaneously labeled with carboxyfluorescein succinimidyl ester (CFSE) dye (eBioscience, San Diego, CA) [62]. Briefly, cells were labeled with CFSE for 24 hours or with $\mathrm{CM}-\mathrm{H}_{2}$ DCFDA for 30 minutes and treated with chemotherapy drug and/ or AZD1208 or DMSO control. Cells were harvested at 8, 24, 48 and 72 hours and fluorescence was measured on a FACSCanto II and analyzed using FlowJo. Divergence in the CFSE and CM- $\mathrm{H}_{2}$ DCFDA curves at serial time points indicates altered ROS generation.

\section{Statistical analysis}

Statistical analysis was performed by two-way ANOVA with post hoc Bonferroni testing, using GraphPad Prism V.

\section{ACKNOWLEDGMENTS}

The authors are grateful to the UMGCC Flow Cytometry Shared Service for providing assistance and consultation.

\section{CONFLICTS OF INTEREST}

AET is an employee of AstraZeneca and DH was an employee of AstraZeneca. The other authors have no competing financial interests in relation to the work described.

\section{GRANT SUPPORT}

Funded by a Merit Review grant from the Department of Veterans Affairs (M.R.B.), Leukemia and Lymphoma Society Translational Research Awards (M.R.B., F.V.R.), NCI grant CA163800 (D.P.), NCI Cancer Center Support Grant P30 CA134274 and University of Maryland, Baltimore UMMG Cancer Research Grant \#CH 649 CRF issued by the State of Maryland Department of Health and Mental Hygiene (DHMH) under the Cigarette Restitution Fund Program.

\section{REFERENCES}

1. Dohner H, Weisdorf DJ, Bloomfield CD. Acute Myeloid Leukemia. The New England Journal of Medicine. 2015; 373:1136-1152. 
2. Rosnet O, Buhring HJ, Marchetto S, Rappold I, Lavagna C, Sainty D, Arnoulet C, Chabannon C, Kanz L, Hannum C, Birnbaum D. Human FLT3/FLK2 receptor tyrosine kinase is expressed at the surface of normal and malignant hematopoietic cells. Leukemia. 1996; 10:238-248.

3. Kiyoi H, Towatari M, Yokota S, Hamaguchi M, Ohno R, Saito H, Naoe T. Internal tandem duplication of the FLT3 gene is a novel modality of elongation mutation which causes constitutive activation of the product. Leukemia. 1998; 12:1333-1337.

4. Schlenk RF, Dohner K, Krauter J, Frohling S, Corbacioglu A, Bullinger L, Habdank M, Spath D, Morgan M, Benner A, Schlegelberger B, Heil G, Ganser A, et al. Mutations and treatment outcome in cytogenetically normal acute myeloid leukemia. The New England Journal of Medicine. 2008; 358:1909-1918.

5. Patel JP, Gonen M, Figueroa ME, Fernandez H, Sun Z, Racevskis J, Van Vlierberghe P, Dolgalev I, Thomas $\mathrm{S}$, Aminova O, Huberman K, Cheng J, Viale A, et al. Prognostic relevance of integrated genetic profiling in acute myeloid leukemia. The New England Journal of Medicine. 2012; 366:1079-1089.

6. Brunet S, Labopin M, Esteve J, Cornelissen J, Socie G, Iori AP, Verdonck LF, Volin L, Gratwohl A, Sierra J, Mohty M, Rocha V. Impact of FLT3 internal tandem duplication on the outcome of related and unrelated hematopoietic transplantation for adult acute myeloid leukemia in first remission: a retrospective analysis. Journal of Clinical Oncology. 2012; 30:735-741.

7. Stone RM, DeAngelo DJ, Klimek V, Galinsky I, Estey E, Nimer SD, Grandin W, Lebwohl D, Wang Y, Cohen P, Fox EA, Neuberg D, Clark J, et al. Patients with acute myeloid leukemia and an activating mutation in FLT3 respond to a small-molecule FLT3 tyrosine kinase inhibitor, PKC412. Blood. 2005; 105:54-60.

8. Metzelder S, Wang Y, Wollmer E, Wanzel M, Teichler S, Chaturvedi A, Eilers M, Enghofer E, Neubauer A, Burchert A. Compassionate use of sorafenib in FLT3-ITD-positive acute myeloid leukemia: sustained regression before and after allogeneic stem cell transplantation. Blood. 2009; 113:6567-6571.

9. Cortes JE, Kantarjian H, Foran JM, Ghirdaladze D, Zodelava M, Borthakur G, Gammon G, Trone D, Armstrong RC, James J, Levis M. Phase I study of quizartinib administered daily to patients with relapsed or refractory acute myeloid leukemia irrespective of FMS-like tyrosine kinase 3-internal tandem duplication status. Journal of Clinical Oncology. 2013; 31:3681-3687.

10. Altman JK, Perl A, Cortes JE, Levis MJ, Smith CC, Litzow MR, Baer MR, Claxton DF, Erba HP, Gill SC, Goldberg SL, Jurcic JG, Larson RA, et al. Antileukemic activity and tolerability of ASP2215 $80 \mathrm{mg}$ and greater in FLT3 mutation-positive subjects with relapsed or refractory acute myeloid leukemia: Results from a phase 1/2, open-label, dose-escalation/dose-response study. Blood. 2015; 126:321(Abstract).

11. Zhang Y, Wang Z, Li X, Magnuson NS. Pim kinasedependent inhibition of c-Myc degradation. Oncogene. 2008; 27:4809-4819.

12. Morishita D, Katayama R, Sekimizu K, Tsuruo T, Fujita N. Pim kinases promote cell cycle progression by phosphorylating and down-regulating p27Kip1 at the transcriptional and posttranscriptional levels. Cancer Research. 2008; 68:5076-5085.

13. Gu JJ, Wang Z, Reeves R, Magnuson NS. PIM1 phosphorylates and negatively regulates ASK1-mediated apoptosis. Oncogene. 2009; 28:4261-4271.

14. Xie Y, Burcu M, Linn DE, Qiu Y, Baer MR. Pim-1 kinase protects $\mathrm{P}$-glycoprotein from degradation and enables its glycosylation and cell surface expression. Molecular Pharmacology. 2010; 78:310-318.

15. Aho TL, Sandholm J, Peltola KJ, Mankonen HP, Lilly M, Koskinen PJ. Pim-1 kinase promotes inactivation of the proapoptotic Bad protein by phosphorylating it on the Ser 112 gatekeeper site. FEBS Letters. 2004; 571:43-49.

16. Kim KT, Baird K, Ahn JY, Meltzer P, Lilly M, Levis M, Small D. Pim-1 is up-regulated by constitutively activated FLT3 and plays a role in FLT3-mediated cell survival. Blood. 2005; 105:1759-1767.

17. Natarajan K, Xie Y, Burcu M, Linn DE, Qiu Y, Baer MR. Pim-1 kinase phosphorylates and stabilizes $130 \mathrm{kDa}$ FLT3 and promotes aberrant STAT5 signaling in acute myeloid leukemia with FLT3 internal tandem duplication. PLoS ONE. 2013; 8:e74653.

18. Green AS, Maciel TT, Hospital MA, Yin C, Mazed F, Townsend EC, Pilorge S, Lambert M, Paubelle E, Jacquel A, Zylbersztejn F, Decroocq J, Poulain L, et al. Pim kinases modulate resistance to FLT3 tyrosine kinase inhibitors in FLT3-ITD acute myeloid leukemia. Science Advances. 2015; 1:e1500221.

19. Chen LS, Redkar S, Taverna P, Cortes JE, Gandhi V. Mechanisms of cytotoxicity to Pim kinase inhibitor, SGI-1776, in acute myeloid leukemia. Blood. 2011; 118:693-702.

20. McEachern KA, Cao Y, DuPont R, Pablo L, McCoon P, Cortes JE, DeAngelo DJ, Minden MD, Hewes B, Brown JL. AZD1208 PIM kinase inhibitor-Preliminary evidence of target pathway inhibition in Phase I clinical trials of AML. Cancer Research. 2013; 73:3516(Abstract)

21. Raab MS, Ocio EM, Thomas SK, Günther A, Goh Y-T, Lebovic D, Jakubowiak A, Song D, Xiang F, Patel A. Phase 1 study update of the novel pan-Pim kinase inhibitor LGH447 in patients with relapsed/refractory multiple myeloma. Blood. 2014; 124:301(Abstract).

22. Koblish H, Shin N, Hall L, O'Connor S, Wang Q, Wang K, Leffet L, Covington M, Burke K, Boer J. Activity of the pan-PIM kinase inhibitor INCB053914 in models of 
acute myelogenous leukemia. Cancer Research. 2015; 75:5416(Abstract).

23. Keeton EK, McEachern K, Dillman KS, Palakurthi S, Cao Y, Grondine MR, Kaur S, Wang S, Chen Y, Wu A. AZD1208, a potent and selective pan-Pim kinase inhibitor, demonstrates efficacy in preclinical models of acute myeloid leukemia. Blood. 2014; 123:905-913.

24. Natarajan K, Mathias TJ, Doshi KA, Tron AE, Kraus M, Trotta R, Perrotti D, Huszar D, Baer MR. The pim kinase inhibitor AZD1208 enhances apoptosis induction by clinically active FLT3 inhibitors in FLT3-ITD acute myeloid leukemia cells in vitro and in vivo through synergistic downregulation of Mcl-1 and of Bcl-xL. Blood. 2014; 124:3601(Abstract)

25. Eiring AM, Harb JG, Neviani P, Garton C, Oaks JJ, Spizzo R, Liu S, Schwind S, Santhanam R, Hickey CJ, Becker $\mathrm{H}$, Chandler JC, Andino R, et al. miR-328 functions as an RNA decoy to modulate hnRNP E2 regulation of mRNA translation in leukemic blasts. Cell. 2010; 140:652-665.

26. Nieborowska-Skorska M, Hoser G, Kossev P, Wasik MA, Skorski T. Complementary functions of the antiapoptotic protein $\mathrm{A} 1$ and serine/threonine kinase pim-1 in the BCR/ABL-mediated leukemogenesis. Blood. 2002; 99:4531-4539.

27. Kerrigan D, Pommier Y, Kohn KW. Protein-linked DNA strand breaks produced by etoposide and teniposide in mouse L1210 and human VA-13 and HT-29 cell lines: relationship to cytotoxicity. NCI Monographs: a Publication of the National Cancer Institute. 1986; 4:117-121.

28. Nitiss JL. Targeting DNA topoisomerase II in cancer chemotherapy. Nature Reviews Cancer. 2009; 9:338-350.

29. Rogakou EP, Pilch DR, Orr AH, Ivanova VS, Bonner WM. DNA double-stranded breaks induce histone H2AX phosphorylation on serine 139. Journal of Biological Chemistry. 1998; 273:5858-5868.

30. Kuo LJ, Yang L-X. $\gamma$-H2AX-a novel biomarker for DNA double-strand breaks. In Vivo. 2008; 22:305-309.

31. Klaunig JE, Kamendulis LM, Hocevar BA. Oxidative stress and oxidative damage in carcinogenesis. Toxicologic Pathology. 2010; 38:96-109.

32. Cooke MS, Evans MD, Dizdaroglu M, Lunec J. Oxidative DNA damage: mechanisms, mutation, and disease. The FASEB Journal. 2003; 17:1195-1214.

33. Fathi AT, Arowojolu O, Swinnen I, Sato T, Rajkhowa T, Small D, Marmsater F, Robinson JE, Gross SD, Martinson M, Allen S, Kallan NC, Levis M. A potential therapeutic target for FLT3-ITD AML: PIM1 kinase. Leukemia Research. 2012; 36:224-231.

34. Spiekermann K, Bagrintseva K, Schwab R, Schmieja K, Hiddemann W. Overexpression and constitutive activation of FLT3 induces STAT5 activation in primary acute myeloid leukemia blast cells. Clinical Cancer Research. 2003; 9:2140-2150.
35. Mizuki M, Fenski R, Halfter H, Matsumura I, Schmidt R, Müller C, Grüning W, Kratz-Albers K, Serve S, Steur C, Büchner T, Kienast J, Kanakura Y, et al. Flt3 mutations from patients with acute myeloid leukemia induce transformation of 32D cells mediated by the Ras and STAT5 pathways. Blood. 2000; 96:3907-3914.

36. Martín-Sánchez E, Odqvist L, Rodríguez-Pinilla SM, Sánchez-Beato M, Roncador G, Domínguez-González B, Blanco-Aparicio C, Collazo AMG, Cantalapiedra EG, Fernández JP. PIM kinases as potential therapeutic targets in a subset of peripheral T cell lymphoma cases. PloS ONE. 2014; 9:e112148.

37. Study of SGI-1776, a PIM kinase inhibitor, in subjects with relapsed/refractory leukemias [https://clinicaltrials.gov/ct2/ show/NCT01239108].

38. Doshi KA, Baldwin PR, Kapoor S, Baer MR. The clinically applicable pan-Pim kinase inhibitor PIM447 sensitizes acute myeloid leukemia cells with FLT3-ITD to apoptosis induction by FLT3 inhibitors and by topoisomerase 2 inhibitors. Cancer Research. 2016; 76:3866(Abstract).

39. Mansat-De Mas V, Bezombes C, Quillet-Mary A, Bettaïeb A, Laurent G, Jaffrézou J-P. Implication of radical oxygen species in ceramide generation, c-Jun N-terminal kinase activation and apoptosis induced by daunorubicin. Molecular Pharmacology. 1999; 56:867-874.

40. Li JJ, Tang Q, Li Y, Hu BR, Ming ZY, Fu Q, Qian JQ, Xiang JZ. Role of oxidative stress in the apoptosis of hepatocellular carcinoma induced by combination of arsenic trioxide and ascorbic acid. Acta Pharmacologica Sinica. 2006; 27:1078-1084.

41. Yang CL, Ma YG, Xue YX, Liu YY, Xie H, Qiu GR. Curcumin induces small cell lung cancer NCI-H446 cell apoptosis via the reactive oxygen species-mediated mitochondrial pathway and not the cell death receptor pathway. DNA and Cell Biology. 2012; 31:139-150.

42. Chiara F, Gambalunga A, Sciacovelli M, Nicolli A, Ronconi L, Fregona D, Bernardi P, Rasola A, Trevisan A. Chemotherapeutic induction of mitochondrial oxidative stress activates GSK $-3 \alpha / \beta$ and Bax, leading to permeability transition pore opening and tumor cell death. Cell Death \& Disease. 2012; 3:e444.

43. Raj L, Ide T, Gurkar AU, Foley M, Schenone M, Li X, Tolliday NJ, Golub TR, Carr SA, Shamji AF. Selective killing of cancer cells by a small molecule targeting the stress response to ROS. Nature. 2011; 475:231-234.

44. Marullo R, Werner E, Degtyareva N, Moore B, Altavilla G, Ramalingam SS, Doetsch PW. Cisplatin induces a mitochondrial-ROS response that contributes to cytotoxicity depending on mitochondrial redox status and bioenergetic functions. PloS ONE. 2013; 8:e81162.

45. Yadav N, Kumar S, Marlowe T, Chaudhary A, Kumar R, Wang J, O'Malley J, Boland P, Jayanthi S, Kumar T. Oxidative phosphorylation-dependent regulation of cancer 
cell apoptosis in response to anticancer agents. Cell Death \& Disease. 2015; 6:e1969.

46. Arnold M, Bissinger R, Lang F. Mitoxantrone-induced suicidal erythrocyte death. Cellular Physiology and Biochemistry. 2014; 34:1756-1767.

47. Rowe LA, Degtyareva N, Doetsch PW. DNA damageinduced reactive oxygen species (ROS) stress response in Saccharomyces cerevisiae. Free Radical Biology and Medicine. 2008; 45:1167-1177.

48. Kang M, So E, Simons A, Spitz D, Ouchi T. DNA damage induces reactive oxygen species generation through the H2AX-Nox1/Rac1 pathway. Cell Death \& Disease. 2012; 3:e249.

49. Song J, An N, Chatterjee S, Kistner-Griffin E, Mahajan S, Mehrotra S, Kraft A. Deletion of Pim kinases elevates the cellular levels of reactive oxygen species and sensitizes to K-Ras-induced cell killing. Oncogene. 2015; 34:3728-3736.

50. Sallmyr A, Fan J, Datta K, Kim KT, Grosu D, Shapiro P, Small D, Rassool F. Internal tandem duplication of FLT3 (FLT3/ITD) induces increased ROS production, DNA damage, and misrepair: implications for poor prognosis in AML. Blood. 2008; 111:3173-3182.

51. Fan J, Li L, Small D, Rassool F. Cells expressing FLT3/ITD mutations exhibit elevated repair errors generated through alternative NHEJ pathways: implications for genomic instability and therapy. Blood. 2010; 116:5298-5305.

52. Godfrey R, Arora D, Bauer R, Stopp S, Muller JP, Heinrich T, Bohmer SA, Dagnell M, Schnetzke U, Scholl S, Ostman A, Bohmer FD. Cell transformation by FLT3-ITD in acute myeloid leukemia involves oxidative inactivation of the tumor suppressor protein-tyrosine phosphatase DEP-1/ PTPRJ. Blood. 2012; 119:4499-4511.

53. Sriskanthadevan S, Jeyaraju DV, Chung TE, Prabha S, $\mathrm{Xu}$ W, Skrtic M, Jhas B, Hurren R, Gronda M, Wang X, Jitkova Y, Sukhai MA, Lin FH, et al. AML cells have low spare reserve capacity in their respiratory chain that renders them susceptible to oxidative metabolic stress. Blood. 2015; 125:2120-2130.

54. Lagadinou ED, Sach A, Callahan K, Rossi RM, Neering SJ, Minhajuddin M, Ashton JM, Pei S, Grose V, O'Dwyer
KM, Liesveld JL, Brookes PS, Becker MW, et al. BCL-2 inhibition targets oxidative phosphorylation and selectively eradicates quiescent human leukemia stem cells. Cell Stem Cell. 2013; 12:329-341.

55. Guo L, Liu X, Jiang Y, Nishikawa K, Plunkett W. DNAdependent protein kinase and ataxia telangiectasia mutated (ATM) promote cell survival in response to NK314, a topoisomerase II $\alpha$ inhibitor. Molecular Pharmacology. 2011; 80:321-327.

56. Kurz EU, Douglas P, Lees-Miller SP. Doxorubicin activates ATM-dependent phosphorylation of multiple downstream targets in part through the generation of reactive oxygen species. Journal of Biological Chemistry. 2004; 279:53272-53281.

57. Altenburg JD, Zhang S, Grimard M, Xue X, Farag SS. Inhibition of PIM kinases mitigates DNA repair responses following anthracycline-induced DNA damage and enhances the anti-tumor activity of doxorubicin against lymphoma cells. Blood. 2014; 124:4505(Abstract).

58. Hsu JL, Leong PK, Ho YF, Hsu LC, Lu PH, Chen CS, Guh JH. Pim-1 knockdown potentiates paclitaxel-induced apoptosis in human hormone-refractory prostate cancers through inhibition of NHEJ DNA repair. Cancer Letters. 2012; 319:214-222.

59. Levis M, Allebach J, Tse KF, Zheng R, Baldwin BR, Smith BD, Jones-Bolin S, Ruggeri B, Dionne C, Small D. A FLT3targeted tyrosine kinase inhibitor is cytotoxic to leukemia cells in vitro and in vivo. Blood. 2002; 99:3885-3891.

60. Quentmeier H, Reinhardt J, Zaborski M, Drexler HG. FLT3 mutations in acute myeloid leukemia cell lines. Leukemia. 2003; 17:120-124.

61. Sen R, Natarajan K, Bhullar J, Shukla S, Fang H-B, Cai L, Chen Z-S, Ambudkar SV, Baer MR. The novel BCR-ABL and FLT3 inhibitor ponatinib is a potent inhibitor of the MDR-associated ATP-binding cassette transporter ABCG2. Molecular Cancer Therapeutics. 2012; 11:2033-2044.

62. Quah BJ, Warren HS, Parish CR. Monitoring lymphocyte proliferation in vitro and in vivo with the intracellular fluorescent dye carboxyfluorescein diacetate succinimidyl ester. Nature Protocols. 2007; 2:2049-2056. 